\section{Mycorrhiza 2009}

\author{
Vivienne Gianinazzi-Pearson • Randy Molina
}

Published online: 16 December 2008

(C) Springer-Verlag 2008

Greetings from the Managing Editors of Mycorrhiza! We would like to take this opportunity to update readers about the journal's progress in the international arena. Since its inception in 1991, the impact factor of Mycorrhiza has steadily increased to reach 2.077 in 2007, with a ranking of sixth among the 19 ISI-listed mycology journals. This noteworthy achievement for a journal with such specialised focus reflects our continual strive to publish original, highvalue research and review articles from scientists world-

V. Gianinazzi-Pearson $(\bowtie)$

Plante-Microbe-Environnement, UMR INRA/CNRS/

Université de Bourgogne,

BP 86510, 21065 Dijon Cedex, France

e-mail: gianina@dijon.inra.fr

R. Molina

625 SE 14th Court,

Gresham, OR 97080, USA wide. Going online, a new cover design and adoption as the official journal of the recently created International Mycorrhiza Society have further promoted Mycorrhiza. Many researchers around the world contribute substantially to enhancing the quality and international recognition of Mycorrhiza both through published papers and reviewing activities. Recognised scientists with diverse specialities in mycorrhiza science regularly serve on Mycorrhiza's Editorial Board, and we would like to reiterate our great appreciation to past members for their dedicated efforts in reviewing and in providing advice to improve the journal's standards. It is also the occasion to announce a newly composed Editorial Board and to offer our sincere thanks to the outgoing members of the previous one for their implication in this important task. We look forward to working with the new Editorial Board and to continuing to improve the journal's standing as an international reference for important research findings in mycorrhiza science. 